\title{
Process Adaption of a Small WWTP Operated at Low Loading Conditions for Substantial Energy Savings
}

\author{
Stig Morling Sweco, Roland Johansson Pireva \\ Sweco Environment AB, Stockholm, Sweden \\ Email: Stig.morling@sweco.se, Roland.Johansson@pireva.se
}

How to cite this paper: Sweco, S.M. and Pireva, R.J. (2020) Process Adaption of a Small WWTP Operated at Low Loading Conditions for Substantial Energy Savings. Journal of Water Resource and Protection, 12, 472-479.

https://doi.org/10.4236/jwarp.2020.126028

Received: April 22, 2020

Accepted: June 2, 2020

Published: June 5, 2020

Copyright $\odot 2020$ by author(s) and Scientific Research Publishing Inc. This work is licensed under the Creative Commons Attribution International License (CC BY 4.0).

http://creativecommons.org/licenses/by/4.0/

\begin{abstract}
The very long tradition of the activated sludge treatment model within the water industry has demonstrated very versatile possibilities to adopt the operation mode for different enhancements. By looking into other treatment models within the activated sludge family it is possible to find alternatives for the operation. This paper concentrates on the possibilities to improve even small WWTP with respect to energy savings. The small plant in Northern Sweden, called Rosvik WWTP, is given as an example. Some important findings related to the intermittent aeration mode may be summarized as follows: 1) An energy savings for the operation of the small WWTP with respect to aeration needs that resulted in a decrease of the energy power supply by more than $35 \%$, as compared with the previous operation based on continuous aeration; 2) The up to date effluent levels with respect to the main pollutants have remained at very good levels in 2020 , P-level averages $0.16 \mathrm{mg} \mathrm{P} / \mathrm{l}$ versus consent level $<0.5 \mathrm{mg} \mathrm{P} / \mathrm{l}$; COD-level 40 versus $<70 \mathrm{mg} / \mathrm{l}$ and $\mathrm{BOD}_{7} 9$ versus $<15 \mathrm{mg} / \mathrm{l}$; 3) Sometimes, also improved sludge settling characteristics have been observed, thus providing improved discharge figures; 4) The potential to develop an enhanced biological phosphorus removal. There are however some needed conditions to accomplish these improvements: 1) Reliable on-line probes for both oxygen control, SS-concentration control and optionally also for nitrogen control; 2) A flexible automation system that allows the needed process modifications to take place; 3) And finally, very important dedicated and competent plant operators, with the needed curiosity for operation improvements.
\end{abstract}

\section{Keywords}

Activated Sludge, Low Load, Energy Savings, Phosphorus Removal, Intermittent Operation 


\section{Introduction}

The activated sludge concept for wastewater treatment is probably by far the most utilised system for organic removal, as well as biological nutrient removal ever since it was first developed by Arden and Lockett in 1915 [1]. The potential flexibility within the system has encouraged several different concept models to occur over a little more than a century. It should be borne in mind that the original configuration was as a matter of fact what we today known as the Sequencing Batch Reactor model. This goes back to the first scale laboratory tests performed in a very simple way, see Figure 1.

The development history of the activated sludge model is indeed a proof of the versatility of the concept. In this context, only a few cornerstones in the development would be mentioned.

- A first development step within the water industry was to take the fundamental concept "on board" but abandon the intermittent aeration mode and replace it by an aeration basin followed by a separate clarifier.

- This model became by far the dominating concept for more than three decades, mainly due to a simple and easily understandable model.

- In the 1950 is the development of the "Oxidation Ditch", especially for small WWTPs became a very important step. This is to be contributed to Dr. Passver, of the Netherlands. The impact of the Oxidation Ditch on a diversified activated sludge technology is illustrated in Figure 2.

- The further development that is still going on took on board the concept again of the intermittent aeration within the activated sludge system. Here only one of the many scientists that were instrumental is mentioned, see professor Robert Irvine [2].

In the following presentation the focus is made on small activated sludge plants in Sweden and starting with a historic background. In many respects it is correct to state that modern waste-water treatment started in Sweden in the late 1960s, when a new environmental law was implemented.

At that time, the environmental concern focused on phosphorus as being by

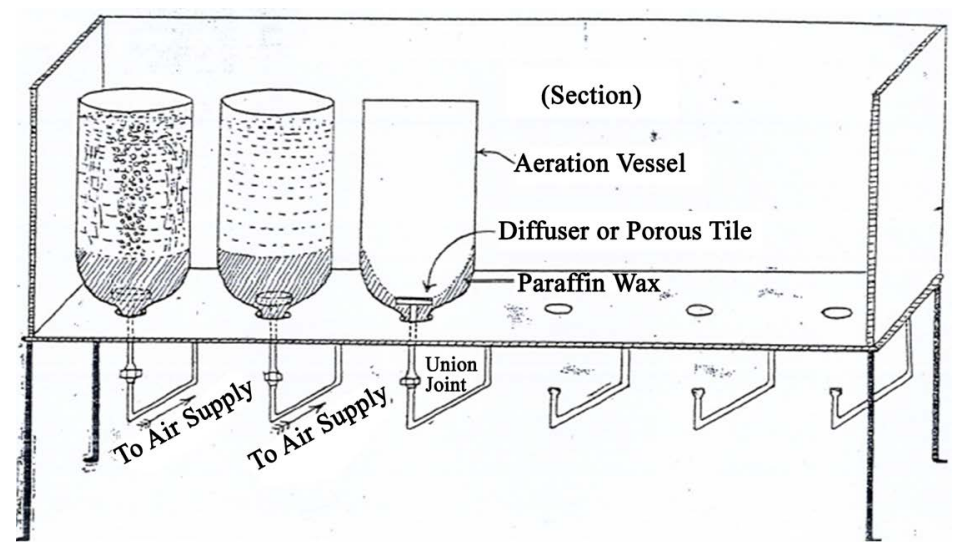

Figure 1. The original SBR-facility used at the tests performed by Arden and Lockett in Manchester 1912-1914. 
OXIDATION DITCH

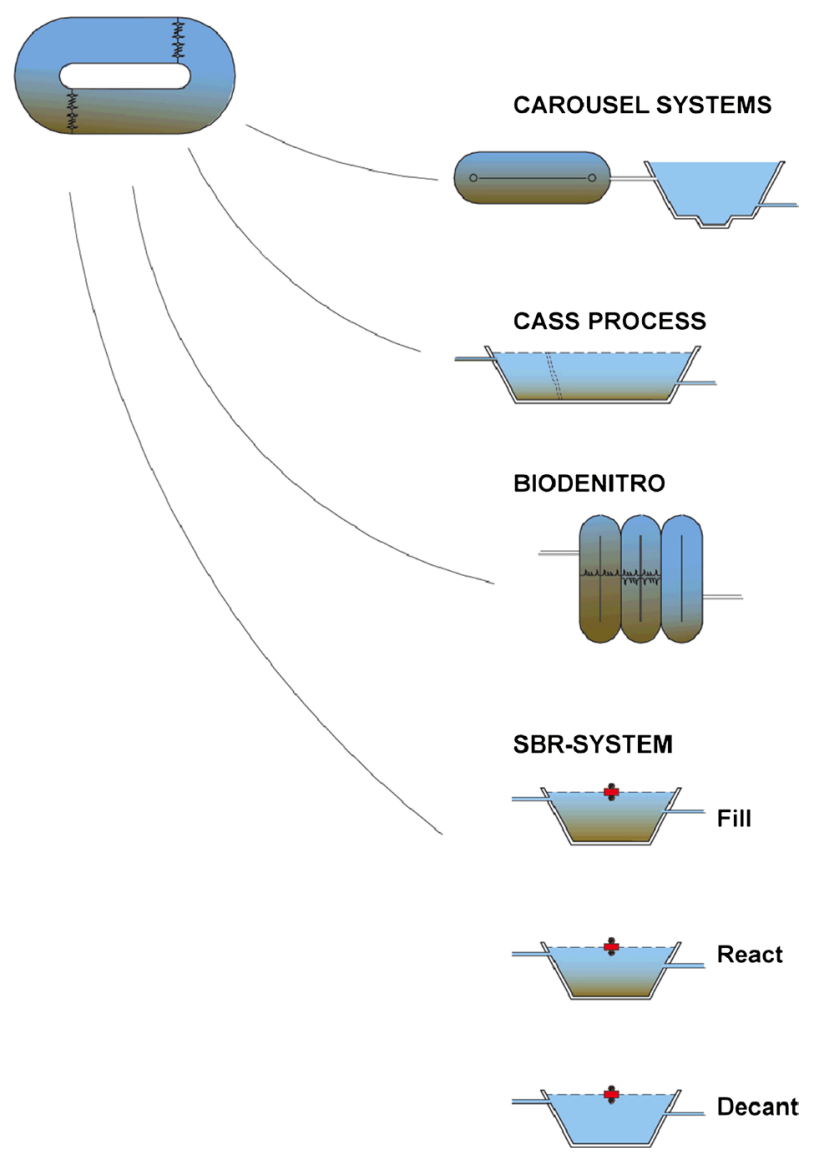

Figure 2. A schematic presentation of the influence by the Oxidation Ditch on different intermittent activated sludge systems.

far the limiting factor for the Swedish water bodies. Once the environmental permits came into power the typical effluent stipulations were normally defined as follows:

$\mathrm{BOD}_{7}<15 \mathrm{mg} / \mathrm{l}$

Total $\mathrm{P}<0.5 \mathrm{mg} \mathrm{P} / \mathrm{l}$.

These permits were initially also given with specific, minimum percentage removal levels, typically $>90 \%$ both for $\mathrm{BOD}$ and $\mathrm{P}$ removal. This may be the starting point of a development of techniques to reduce especially phosphorus in the municipal wastewater discharge, see Morling, S. [3]. To successfully comply with these new standards a rather uniform technical solution developed during almost a decade in Sweden. For smaller plants, in this context defined as municipal WWTPs serving communities up to around 10,000 person equivalents. A very typical treatment scheme is illustrated in Figure 3.

The treatment chain was basically built with three stages:

- A pretreatment based on a mechanical screen followed by an aerated sand trap;

- The biological treatment based on the activated sludge model, and sized for the removal of organic compounds; 
- A post-precipitation stage, based on the addition of alum or ferric salts, flocculation and sludge separation.

\section{Objectives}

The objective of this study is to present the potentials to operate conventionally designed activated sludge plants intermittently. Examples are given from some plants where substantial energy savings are achieved by the intermittent operation.

\section{Material and Methods}

In the following, three different plants will be discussed, all operated by intermittent operation. Two of these plants have been presented previously, see [4] and [5]. One plant is a plant operating in Sri Lanka, labelled Ja-Ela WWTP (Wastewater Treatment Plant) and the second one is a plant in the center part of Sweden, labelled Solviken WWTP, serving the community of Mora, Dalecarlia.

The focus in this study is a small municipal WWTP facility located in the northern part of Sweden, own and operated by the public company PIREVA, owned by the community of Piteå. The plant is named Rosvik in the following. The plant was built in the late 1970s, sized for 2500 person equivalents. The process configuration and main design figures are shown in Figure 3.

All operation data and presented analysis results are based on continuous sampling and process control reported from the different plants.

\section{Results and Discussion}

The WWTP plant built outside Colombo, Sri Lanka was initially (years 2011-2012) operated at load conditions, substantially lower than the design levels. Actions were taken to safeguard a feasible operation mode. The results were quite acceptable, and presented in a scientific paper, see [4], the results are summarized in the paper, quote:

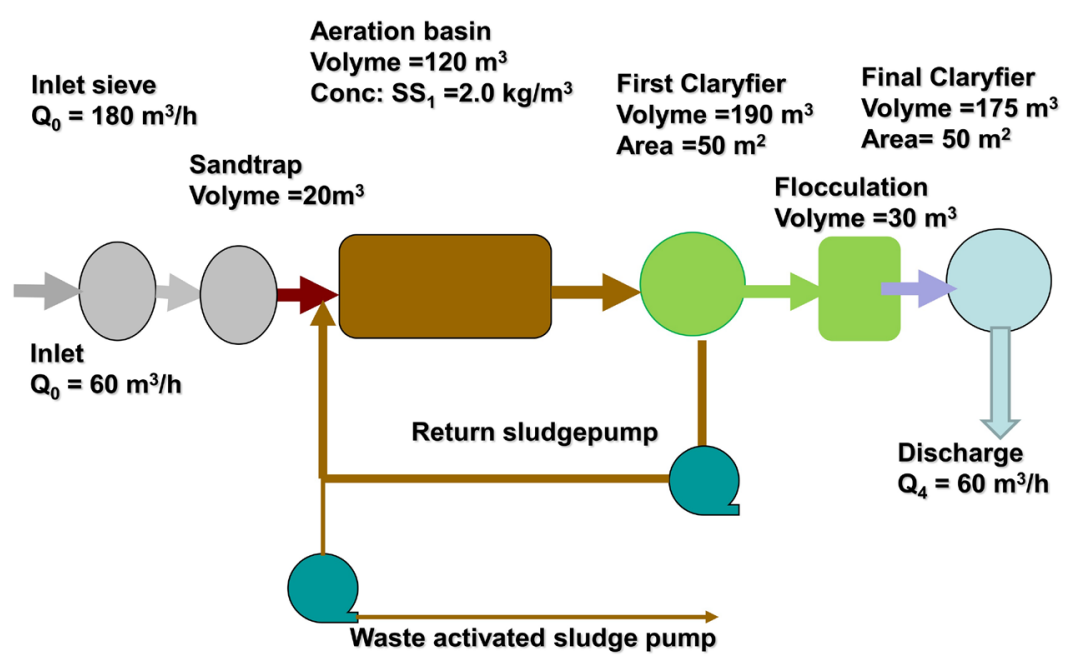

Figure 3. Simplified flowsheet for Rosvik WWTP. 
"The intermittent operation has enabled an energy efficient operation of the plant. By the introduction of the intermittent aeration the energy consumption has been reduced by around $75 \%$, compared with the continuous operation mode".

- The plant performance during the intermittent operation has been improved with respect to virtually all-important pollution variables. The most striking improvement is the discharge total P level, reflecting that a substantial enhanced biological phosphorus removal takes place;

- The typical discharge levels were found during May 2012 were compared with the earlier obtained values. It is important to underline that the loading on the plant has slightly increased during May as compared with the previous operation period.

The municipal plant for the town of Mora, Sweden was initially built in the early 1970s, and extended and modified a few times. A Master Thesis was performed in 2014, inter alia studying the potentials for energy saving by an intermittent operation of the aeration basins. The main findings have been summarized as follows, see [5], quote:

"A biological wastewater treatment serving Mora community, in middle part Sweden, is treating municipal wastewater and septic sludge. The plant has been operated with an intermittent aeration of the activated sludge step since springtime 2015. The objective has been to find an efficient pathway to save energy from the blowers. The operation has been followed up closely. The plant has been operated at a low water temperature, mainly $<10^{\circ} \mathrm{C}$. Additionally the plant has been operated almost at design loading conditions, with respect to organic matters. The results with respect to energy savings are summarized as follows: A $30 \%$ to $40 \%$ reduction in aeration time per day has been established. The results so far indicate a pathway towards further energy savings at the plant. At the same time, the effluent discharge levels have been reached, normally with a substantial margin".

Based on these interesting results the PIREVA company considered the possibilities to include an intermittent operation of the aeration basin at the Rosvik plant. The main reason was the rather low load of the plant, compared to the design load. Table 1 summarizes the main design loads compared with the loading figures from 2013-2015.

Comments to the actual load figures: As found in the table, the actual loads are typically less than $50 \%$ of design loads, except for $\mathrm{BOD}_{7}$ being typically around $50 \%$ of design load.

Thus, in 2016 a test operation started at the plant with an intermittent aeration of the activated sludge. The typical scheme was as follows.

The operation cycle, covering both the aeration, non-aeration and withdrawal of excess sludge during the test period was 3 hours, with the following actions.

- The aeration time was 120 minutes (2 hours). 
Table 1. Summary of design figures and loads on the Rosvik WWTP, PIREVA, Sweden.

\begin{tabular}{cccccc}
\hline Parameter & Design values & Load 2013 & Load 2014 & Load 2015 & \\
\hline Daily flow & 1000 & 404 & 339 & 602 & $\mathrm{~m}^{3} / \mathrm{d}$ \\
Design flow & 60 & 17 & 14 & 25 & $\mathrm{~m}^{3} / \mathrm{h}$ \\
Pollution loads & & 52 & 86 & 88 & $\mathrm{~kg} / \mathrm{d}$ \\
BOD $_{7}$ & 175 & 151 & 181 & 180 & $\mathrm{~kg} / \mathrm{d}$ \\
COD & $(425)$ & $\underline{2.15}$ & $\underline{2.25}$ & $\underline{1.91}$ & $\underline{\mathrm{kg} / \mathrm{d}}$ \\
$\underline{\text { Tot-P }}$ & $\underline{10}$ & & & &
\end{tabular}

Remark: The organic variable, expressed as $\mathrm{BOD}_{7}$ is understood as Biochemical Oxygen Demand, for seven days. This is an alteration within the Nordic and Baltic countries from the conventional $\mathrm{BOD}_{5}$, used in most countries. The basis is the 5-day working week in these countries.

- The non-aeration time was 60 minutes (1 Hour).

- During the aeration time, waste activated sludge was removed from the biological step and chemical sludge from the chemical precipitation. This was necessary, as all internal sludge pumping was based on airlift pumping.

- The sludge scraper in the chemical stage operated for 60 minutes during each cycle.

- The sludge scraper in the biological clarifier was operated continuously.

The results during the test period were better than expected, and the following main conclusions were drawn from the operation:

The discharge values for the ruling permit variables were kept with a good margin, $\mathrm{BOD}_{7}$-concentration was almost consistently around $10 \mathrm{mg} / \mathrm{l}$, compared with the consent level of $<15 \mathrm{mg} / \mathrm{l}$. The discharge P-level, presented as a mean value, was found to be $0.35 \mathrm{mg} / \mathrm{l}$, compared with the ruling consent level of $<0.5$ $\mathrm{mg} / \mathrm{l}$.

Consequently, the annual energy savings for the plant was $18,000 \mathrm{kWh}$, or $1 / 3^{\text {rd }}$ of the previous energy needs for the biological treatment step $(55,000 \mathrm{kWh} /$ year).

Based on these findings PIREVA decided to evaluate a permanent operation of the Rosvik WWTP using an intermittent operation. In a longer perspective it would also be interesting to evaluate the potentials of an enhanced biological phosphorus removal at the plant.

After an operation for two years with the intermittent aeration an evaluation was done at site. Some interesting observations were found:

- Even during the intermittent aeration, the free oxygen level in the aeration basin would reach $4 \mathrm{mg} \mathrm{O}_{2} / \mathrm{l}$ on a regular basis. At a site visit in May 2019 it was found the oxygen level reached $7 \mathrm{mg} \mathrm{O}_{2} / 1$.

- This circumstance indicated that a further cut of the aerated time in the bioreactor was possible. However, this needed an on-line automation control based on the installed oxygen meter. This in turn called for an additional automatic steering program. A suitable stop-level for the blower operation would be $2.0-2.5 \mathrm{mg} \mathrm{O}_{2} / 1$. 
- Further it was suggested that the return activated sludge pumps could be operated in an intermittent mode, for an additional energy saving.

These actions were all implemented during 2019.

Some of the actions were included for the ongoing operation, and the intermittent operation continued. In early 2020, the discharge levels from the Rosvik WWTP were indeed very satisfying, as shown in Table 2.

Comments to the latest results: The discharge levels are all found as being more than required. These results have further encouraged PIREVA to consider a "twin plant" called Norrfjaerden to be converted into the same intermittent mode. Accordingly, the very good P-removal levels indicate a possibility to develop a certain biological P-removal level, see for instance findings earlier during similar climatic and geographical conditions [6].

\section{Conclusions}

The very long tradition of the activated sludge treatment model within the water industry has demonstrated very versatile possibilities to adopt the operation mode for different enhancements. By looking into other treatment models within the activated sludge family it is possible to find alternatives for the operation. Some important findings related to the intermittent aeration mode may be summarized as follows:

- An energy savings for the operation, as described above;

- Sometimes, also improved sludge settling characteristics thus providing improved discharge figures;

Table 2. Summary of discharge levels and (consent levels) at the Rosvik WWTP, PIREVA, Sweden the first quarter of 2020.

\begin{tabular}{ccccc}
\hline Date & Flow $\mathrm{m}^{3} / \mathrm{d}$ & tot-P $(<0.5)$ & COD $(<70)$ & BOD $(<15)$ \\
\hline $2020-01-02$ & 255 & 0.26 & 40 & 9 \\
$2020-01-08$ & 266 & 0.28 & 39 & 11 \\
$2020-01-16$ & 748 & 0.23 & 40 & 11 \\
$2020-01-21$ & 1014 & 0.14 & 43 & 11 \\
$2020-01-29$ & 676 & 0.07 & 39 & 8 \\
$2020-02-04$ & 928 & 0.1 & 38 & 8 \\
$2020-02-12$ & 861 & 0.1 & 35 & 7 \\
$2020-02-19$ & 929 & 0.13 & 37 & 9 \\
$2020-02-25$ & 734 & 0.2 & 38 & 8 \\
$2020-03-04$ & 1000 & 0.15 & 44 & 9 \\
$2020-03-12$ & 683 & 0.1 & 42 & 9 \\
$2020-03-19$ & 886 & 0.12 & 52 & \\
$2020-03-25$ & & 0.2 & 46 & \\
Quarter 1 & 748 & 0.16 & 41 & \\
\hline
\end{tabular}


- The potential to develop an enhanced biological phosphorus removal; There are however some needed conditions to accomplish these improvements:

- Reliable on-line probes for both oxygen control, SS-concentration control and optionally also for nitrogen control;

- A flexible automation system that allows the needed process modifications to take place;

- And finally, very important dedicated and competent plant operators, with the needed curiosity for operation improvements.

\section{Acknowledgements}

The text has been scrutinized by Mr. Guy Taylor in a very competent way, thank you. Further we convey our gratitude to all the competent women and men working at PIREVA for their excellent day-by-day work in the water protection field, not the least the contributions for the Rosvik plant.

\section{Conflicts of Interest}

The authors declare no conflicts of interest regarding the publication of this paper.

\section{References}

[1] Arden, E. and Lockett, W.T. (1915) The Oxidation of Sewage without the Aid of Filters. Journal of the Society of Chemical Industry, 827-943.

[2] Irvine, R. (1983) Technology Assessment of Sequencing Batch Reactors. Contract No. 68-03-3055 U.S. Environmental Protection Agency, Cincinnati, pp. 1-70.

[3] Morling, S. (2019) Swedish Experience and Excellence in Wastewater Treatment Demonstrated Especially in Phosphorus Removal. Journal of Water Resource and Protection, 11, 333-347. http://www.scirp.org/journal/jwarp

https://doi.org/10.4236/jwarp.2019.113019

[4] Berg, J. and Morling, S. (2013) Process Adaption and Modifications of a Nutrient Removing Wastewater Treatment Plant in Sri Lanka Operated at Low Loading Conditions. Materials Sciences and Applications, 4, 299-306.

https://doi.org/10.4236/msa.2013.45038

[5] Morling, S., et al. (2016) Energy Savings and Process Performance at a WWTP Operated with Intermittent Aeration at Low Temperature and High Organic Load. The $13^{\text {th }}$ IWA Leading Edge Conference on Water and Wastewater Technologies, Jerez de la Frontera, 13-16 June 2016.

[6] Marklund, S. and Morling, S. (1994) Biological Phosphorus Removal at Temperatures from $3^{\circ} \mathrm{C}$ to $10^{\circ} \mathrm{C}-\mathrm{A}$ Full Scale Study of a Sequencing Batch Reactor Unit. Canadian Journal of Civil Engineering, 21, 81-88. https://doi.org/10.1139/194-008 